\title{
Double-Glide Method Using Cathereep Protective Sheet As a Substitute in Descemet's Stripping Automated Endothelial Keratoplasty
}

\author{
Hiroshi Toshida, ${ }^{1}$ Rio Honda, ${ }^{1}$ Asaki Matsui, ${ }^{1}$ Yusuke Matsuzaki, ${ }^{1}$ Yusuke Shimizu, \\ Takahiko Seto, ${ }^{1}$ Toshihiko Ohta, ${ }^{1}$ and Akira Murakami ${ }^{2}$ \\ ${ }^{1}$ Department of Ophthalmology, Juntendo University Shizuoka Hospital, 1129, Nagaoka, Izunokuni, Shizuoka 410-2295, Japan \\ ${ }^{2}$ Department of Ophthalmology, Juntendo University School of Medicine, 2-1-1, Hongo, Bunkyo, Tokyo 113-8421, Japan
}

Correspondence should be addressed to Hiroshi Toshida; toshida@juntendo.ac.jp

Received 30 May 2012; Accepted 31 July 2012

Academic Editors: H.-J. Kim and W. Lim

Copyright (c) 2013 Hiroshi Toshida et al. This is an open access article distributed under the Creative Commons Attribution License, which permits unrestricted use, distribution, and reproduction in any medium, provided the original work is properly cited.

Purpose. For the insertion of the donor graft in Descemet's stripping automated endothelial keratoplasty (DSAEK), the double-glide method using a Busin glide and intraocular lens (IOL) glide concomitantly has been shown to be effective. The aim of this report is to evaluate the results for the double-glide method using Cathereep (Nichiban, Tokyo, Japan), a protective sheet made of polyurethane film for medical use, as a substitute for an IOL glide. Materials and Methods. The subjects were 10 eyes of 10 patients with bullous keratopathy. The DSAEK operation was performed, and the double-glide method was used for the donor graft insertion. During the operation, an IOL glide was used for the 5 eyes, and the Cathereep protection sheet was used for the remaining 5 eyes. We trimmed approximately $5 \mathrm{~mm}$ wide strips from the nonadhesive area surrounding the Cathereep protection sheet. Results. The donor graft was inserted equally easily with the Cathereep protective sheet and IOL glides and improvement of visual acuity was noted in both groups significantly. A favorable postoperative course was obtained with no perioperative complications including endothelial damage. Conclusions. Cathereep protective sheet can be used as a substitute for an IOL glide for double-glide method in DSAEK.

\section{Introduction}

The operative procedure of keratoplasty has progressed rapidly since the end of the twenty century, and implantations for lesions on a layer-by-layer basis are gradually becoming popular. High among the most popular methods of treating bullous keratopathy over the last decade is Descemet's stripping automated endothelial keratoplasty (DSAEK) [1-4].

The safety and reliability of the DSAEK procedure is founded upon experimentation with measures designed to minimize the damage to corneal endothelial cells at the time of drawing donor cells into the anterior chamber. One method for the insertion of donor graft is a double-glide method using a Busin glide [5] and an intraocular lens (IOL) glide concomitantly for drawing the donor graft. The usefulness of this method has been reported by Kobayashi et al., and the procedure is increasingly popular [6]. The IOL glide
(Alcon Laboratories, Fort Worth, TX, USA) is used to prevent damage to corneal endothelial cells due to direct contact of the donor cells with the iris. Unfortunately, however, the IOL glides are no longer in production, which may interfere with future operations.

We found favorable results obtained in the double-glide method using Cathereep (Nichiban Co. Ltd, Tokyo, Japan) protective sheet made of polyurethane film for medical use, as a substitute for the IOL glide.

\section{Materials and Methods}

Our study was approved by the institutional review board of Juntendo University Shizuoka Hospital. All patients provided informed consent, and this study was conducted in accordance with the Declaration of Helsinki. The subjects were 10 eyes of 10 patients who visited our hospital between 
TABLE 1: Details in 10 participants.

\begin{tabular}{|c|c|c|c|}
\hline & Age (y.o.) & Sex & Primary diseases \\
\hline \multicolumn{4}{|l|}{ IOL glide group } \\
\hline Case 1 & 60 & Female & Fuch's dystrophy \\
\hline Case 2 & 85 & Female & Cataract surgery \\
\hline Case 3 & 78 & Female & Argon laser iridotomy \\
\hline Case 4 & 81 & Male & Endothelitis \\
\hline Case 5 & 91 & Female & Cataract surgery \\
\hline Average & $79.0 \pm 11.7$ & & \\
\hline \multicolumn{4}{|l|}{ Cathereep group } \\
\hline Case 6 & 81 & Male & Cataract surgery \\
\hline Case 7 & 77 & Female & Argon laser iridotomy \\
\hline Case 8 & 91 & Female & Argon laser iridotomy \\
\hline Case 9 & 85 & Male & Cataract surgery \\
\hline Case 10 & 58 & Male & Cataract surgery \\
\hline Average & $79.8 \pm 13.3$ & & \\
\hline Average in total & $79.4 \pm 11.8$ & & \\
\hline
\end{tabular}

Italic showed average \pm standard deviation.

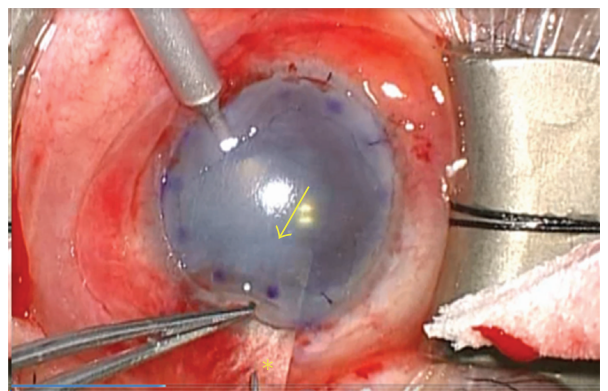

(a)

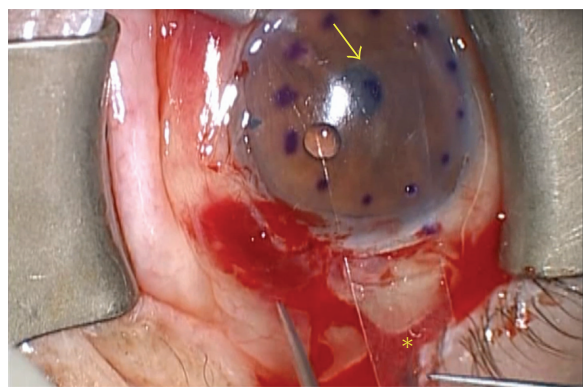

(b)

FIGURE 1: Microscopic images during surgery. Incision of intraocular lens glide in case 4 (a) and Cathereep protection sheet (b) in case 7 into the anterior chamber. Asterisks show intraocular lens glide or Cathereep protection sheet trimmed with 5.0mm width. Arrows show the top of them.

June 2010 and December 2011 and who were diagnosed as having bullous keratopathy which required DSAEK. The details of participants were shown in Table 1. We divided 10 participants in two groups; 5 eyes of 5 cases in the IOL glide using group (IOL glide group) and another 5 eyes of 5 cases in the group using Cathereep protection sheet as a substitute (Cathereep group).

2.1. Surgical procedures. DSAEK was performed in all cases, and for the double-glide method, an IOL glide which has been reported by Kobayashi et al. [6] was used in 5 cases, while Cathereep protection sheet was used for the remaining 5 cases. The operative procedure is summarized as follows:

(1) Descemet's membrane was removed only for DSAEK surgery, except for non-Descemet stripping automated endothelial keratoplasty (nDSAEK) surgery.

(2) An anterior chamber maintainer was inserted to maintain intraocular pressure.

(3) Either an intraocular lens (IOL) glide, or Cathereep protection sheet, after trimming with $5.0 \mathrm{~mm}$ width, was inserted through the $5.1 \mathrm{~mm}$ corneal incision (Figure 1).

(4) A precut donor was punched out using a trepan, and endothelial strips were collected.

(5) An endothelial strip was placed on the Busin glide for insertion, slid along the IOL glide using forceps and inserted into the anterior chamber.

(6) After suturing of the corneal incision, air was injected into the anterior chamber and adhered "gas tamponade".

(7) Corneal paracentesis was carried out, to remove anterior chamber liquid from between the layers

(8) Therapeutic soft contact lenses were applied.

Details of the Cathereep protection sheet trimming method are explained below. Adhesive was applied to one side of the square-shaped Cathereep (no. 1820), except for approximately a $5 \mathrm{~mm}$ width. The nonadhesive surrounding area, which was used for this operative procedure, was cut approximately $5 \mathrm{~mm}$ wide and a little longer length at first. 


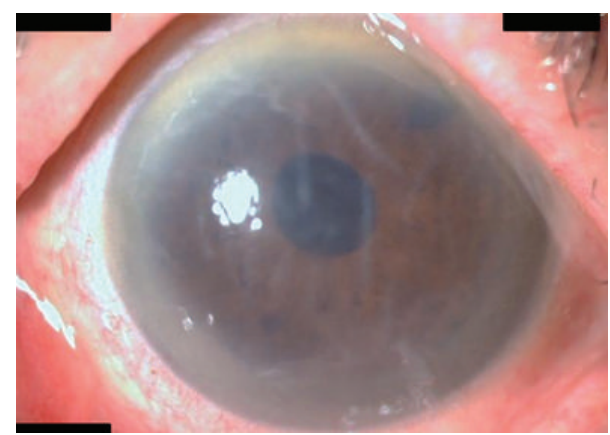

(a)

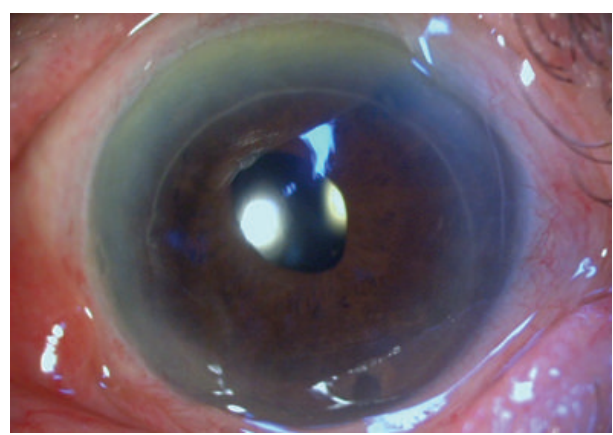

(b)

Figure 2: Slitlamp microscopic pre- and postoperative images in case 7. Seventy-seven years old female showed bullous keratopathy with corneal opacity, and fold of Descemet's membrane at the first visit (a). These findings have disappeared after at 3 months after surgery (b).

Next, the strip was cut to $30 \mathrm{~mm}$ length, and the corner on one side was trimmed to make a semicircular shape. The trimmed shape was similar to the IOL glide used to facilitate insertion via the corneal incision into the anterior chamber.

2.2. Examinations. The endpoints were spectacle-corrected visual acuity and corneal endothelial cell density. Refractometry and keratometry were performed using an ARK-700A (Nidek, Aichi, Japan), corneal endothelial cell density was measured with a Noncon Robo NSP-7700 (Konan Medical Corp., Hyogo, Japan) before and 6 months after surgery. Visual acuity was measured using a Snellen eye chart before and 1 week, 1,3 , and 6 months after surgery as same as previously reported [7]. To analyze the data, each value was converted to logarithm of the minimum angle of resolution (LogMAR) value before comparisons were performed $[8,9]$.

2.3. Statistical Analysis. The paired t-test was performed to compare visual acuity before and after surgeries. All statistical tests were two-sided and significance was accepted at $P<0.05$. Data were shown as the mean \pm standard deviation.

\section{Results}

The mean age of 10 cases was $79.4 \pm 11.8$ years (range 58 years to 91 years). Bullous keratopathy was secondary to postcataract surgery $(n=5)$, argon laser iridotomy $(n=3)$, corneal endothelitis $(n=1)$, and Fuch's dystrophy $(n=$ 1) (Table 1). All cases had already received cataract surgery. There were no complications in all cases during and after DSAEK or non-Descemet stripping automated endothelial keratoplasty (nDSAEK) surgeries and bullous keratopathy has disappeared (Figure 2). The mean preoperative spectaclecorrected visual acuity in LogMAR was $1.38 \pm 0.40$ in the IOL glide group $(n=5)$ and $1.24 \pm 0.34$ in the Cathereep group $(n=5)$. When comparing with the preoperative mean value, mean values at 1,3 , and 6 months after operation were $0.38 \pm 0.16(P=0.005), 0.26 \pm 0.15(P=0.005)$, and $0.23 \pm 0.18(P=0.005)$ in the IOL-glide group, respectively, and $0.63 \pm 0.36(P=0.101), 0.27 \pm 0.13(P=0.003)$, and $0.18 \pm 0.13(P=0.002)$ in the Cathereep group, respectively. Significant improvement of visual acuity was shown compared with preoperative values in both groups (Figure 3). No differences were observed between the two groups. No case remained bullous keratopathy in both groups. The mean corneal endothelial cell density before surgery was $554.4 \pm 224.4$ cells $/ \mathrm{mm}^{2}$ in the IOL group and $532.3 \pm$ 143.5 cells $/ \mathrm{mm}^{2}$ in the Cathereep group, and donor was $2815.2 \pm 159.7$ cells $/ \mathrm{mm}^{2}$ and $2911.0 \pm 213.1$ cells $/ \mathrm{mm}^{2}$ in each group respectively. The mean corneal endothelial cell density at 6 months after surgery was $2135.4 \pm 573.8 \mathrm{cells} / \mathrm{mm}^{2}$ and $2085.2 \pm 707.4$ cells $/ \mathrm{mm}^{2}$ in each group respectively. The mean corneal endothelial cell survival rate at 6 months after operation compared to the preoperative donor cornea rate was $75.9 \%$ in the IOL group and $71.6 \%$ in the Cathereep group, showing similar results in both groups.

\section{Discussion}

During the DSAEK operation, it is important to minimize the damage to corneal epithelial cells $[5-7,10]$. For this purpose, various operative procedures and devices such as an injector are being developed. Among the operative procedures reported, the double-glide method is one of the safest and most convenient. Current marketing discontinuation of the IOL glide is hampering the procedure. Although another manufacturer makes a similar film, it is often unavailable outside the country of manufacture. Therefore, we focused on the Cathereep protective sheet, a sterilized film which is attached to the skin surrounding the injection site of an indwelling Surflo catheter. This sheet is made of polyurethane film and contains no ingredients which may elute. The strength is similar to an IOL glide, and it is colorless and transparent. Although trimming is needed for the operation, it is not a new issue, because trimming was necessary for the IOL glide to adjust the width. The most notable difference in the trimming method is that the corner on one side must be cut to make semicircular shape to facilitate insertion into the anterior chamber. However, this is also simple because it is trimmed only to imitate the shape of IOL glide. 


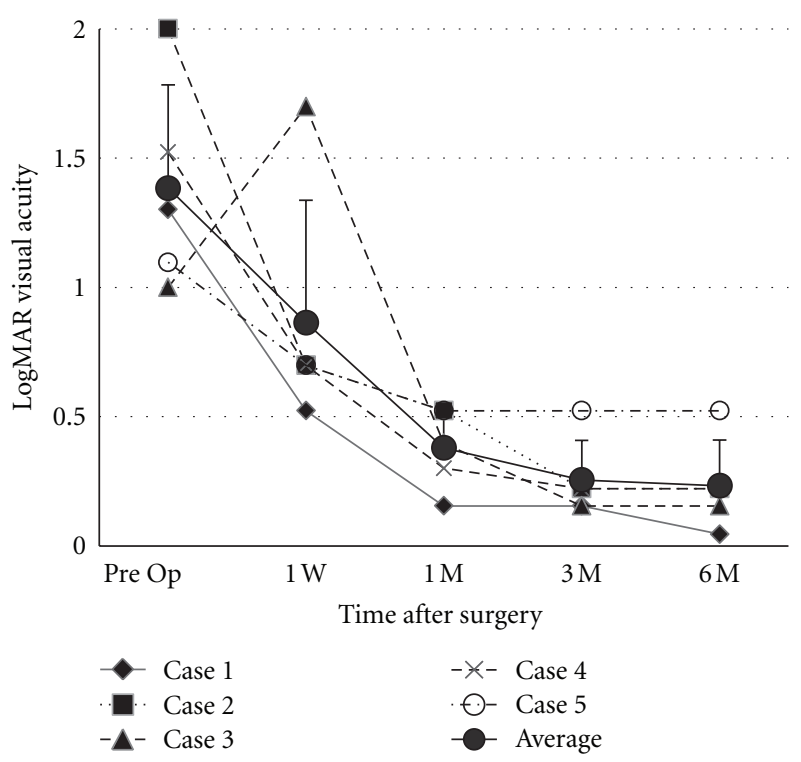

(a)

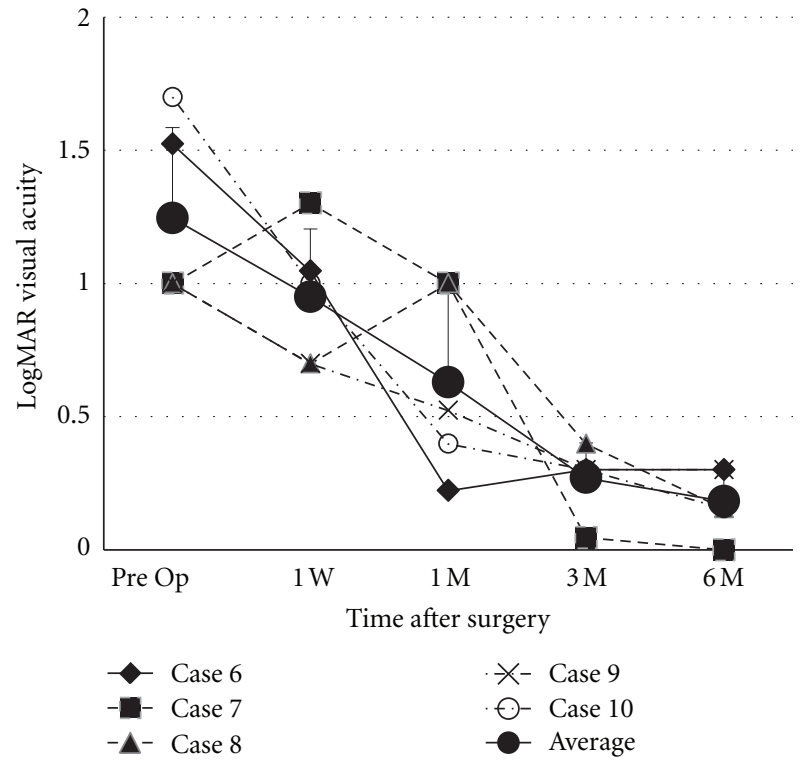

(b)

FIGURE 3: Visual acuity before and after surgery. Changes of pre- and postoperative spectacle-corrected visual acuity in logarithm of the minimum angle of resolution (LogMAR) value in intraocular lens (IOL) glide group (a) and Cathereep group (b). Visual acuity was significantly improved in both groups.

Currently, donor insertion techniques are being developed by a number of ophthalmologists [10-12]. When the safety and effectiveness has been demonstrated, improved devices are expected to appear and become popular in future. However, at this time, as a substitute for IOL glide which is necessary for double-glide method, we found the Cathereep protective sheet useful.

\section{Conclusion}

The handle ability of Cathereep during surgery was quite similar to that of the IOL glide. The postoperative results, including visual acuity, corneal endothelial cell density, and corneal endothelial cell survival rate were also similar to IOL glide. Based on these results, we considered that a Cathereep protective sheet can be used as a substitute for an IOL glide, although long term observation was necessary.

\section{Conflict of Interests}

The authors declared that there is no conflict of interests.

\section{References}

[1] G. R. J. Melles, F. A. G. J. Eggink, F. Lander et al., "A surgical technique for posterior lameliar keratoplasty," Cornea, vol. 17, no. 6, pp. 618-626, 1998.

[2] F. W. Price Jr. and M. O. Price, "Descemet's stripping with endothelial keratoplasty in 50 eyes: a refractive neutral corneal transplant," Journal of Refractive Surgery, vol. 21, no. 4, pp. 339345, 2005.
[3] M. S. Gorovoy, "Descemet-stripping automated endothelial keratoplasty," Cornea, vol. 25, no. 8, pp. 886-889, 2006.

[4] M. A. Terry, N. Shamie, E. S. Chen, P. M. Phillips, K. L. Hoar, and D. J. Friend, "Precut tissue for descemet's stripping automated endothelial keratoplasty. Vision, astigmatism, and endothelial survival," Ophthalmology, vol. 116, no. 2, pp. 248-256, 2009.

[5] M. Busin, P. R. Bhatt, and V. Scorcia, "A modified technique for descemet membrane stripping automated endothelial keratoplasty to minimize endothelial cell loss," Archives of Ophthalmology, vol. 126, no. 8, pp. 1133-1137, 2008.

[6] A. Kobayashi, H. Yokogawa, and K. Sugiyama, "Descemet stripping with automated endothelial keratoplasty for bullous keratopathies secondary to argon laser iridotomy-preliminary results and usefulness of double-glide donor insertion technique," Cornea, vol. 27, no. 1, pp. S62-S69, 2008.

[7] H. Toshida, T. Ohta, MurakamiA, A. Kobayashi, and Y. Sugiyama, "Descemet stripping automated endothelial keratoplasty for microcornea," apanese Journal of Ophthalmology, vol. 56, no. 5, pp. 436-440, 2012.

[8] J. T. Holladay and T. C. Prager, "Mean visual acuity," American Journal of Ophthalmology, vol. 111, no. 3, pp. 372-374, 1991.

[9] F. L. Ferris III, A. Kassoff, G. H. Bresnick, and L. Bailey, "New visual acuity charts for clinical research," American Journal of Ophthalmology, vol. 94, no. 1, pp. 91-96, 1982.

[10] W. B. Khor, J. S. Mehta, and D. T. H. Tan, "Descemet stripping automated endothelial keratoplasty with a graft insertion device: surgical technique and early clinical results," American Journal of Ophthalmology, vol. 151, no. 2, pp. 223.e2-232.e2, 2011.

[11] C. Macaluso, "Closed-chamber pulling-injection system for donor graft insertion in endothelial keratoplasty," Journal of Cataract and Refractive Surgery, vol. 34, no. 3, pp. 353-356, 2008. 
[12] J. S. Mehta, Y. M. Por, R. W. Beuerman, and D. T. Tan, "Glide insertion technique for donor cornea lenticule during Descemet's stripping automated endothelial keratoplasty," Journal of Cataract and Refractive Surgery, vol. 33, no. 11, pp. 18461850, 2007. 


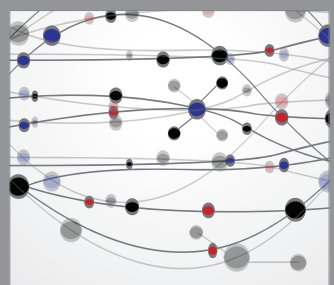

The Scientific World Journal
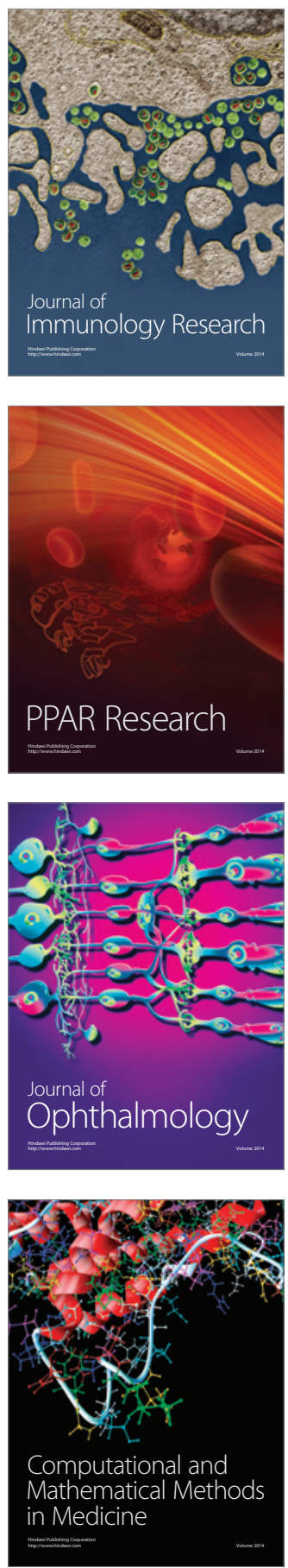

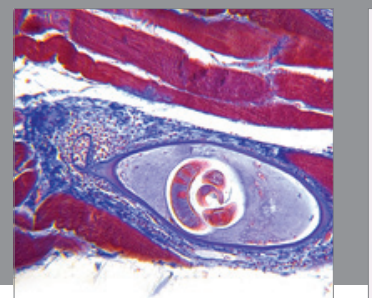

Gastroenterology

Research and Practice
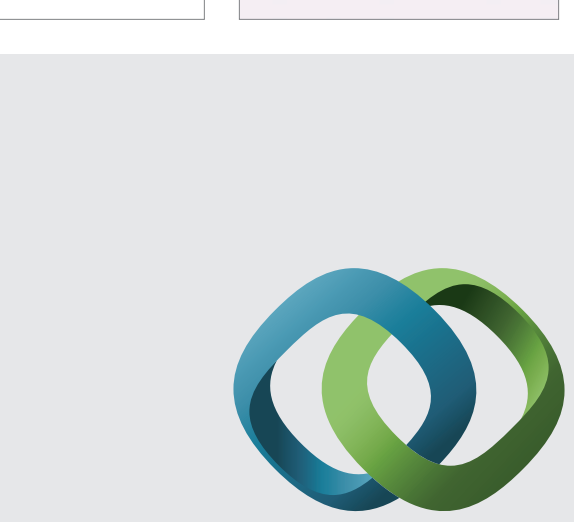

\section{Hindawi}

Submit your manuscripts at

http://www.hindawi.com
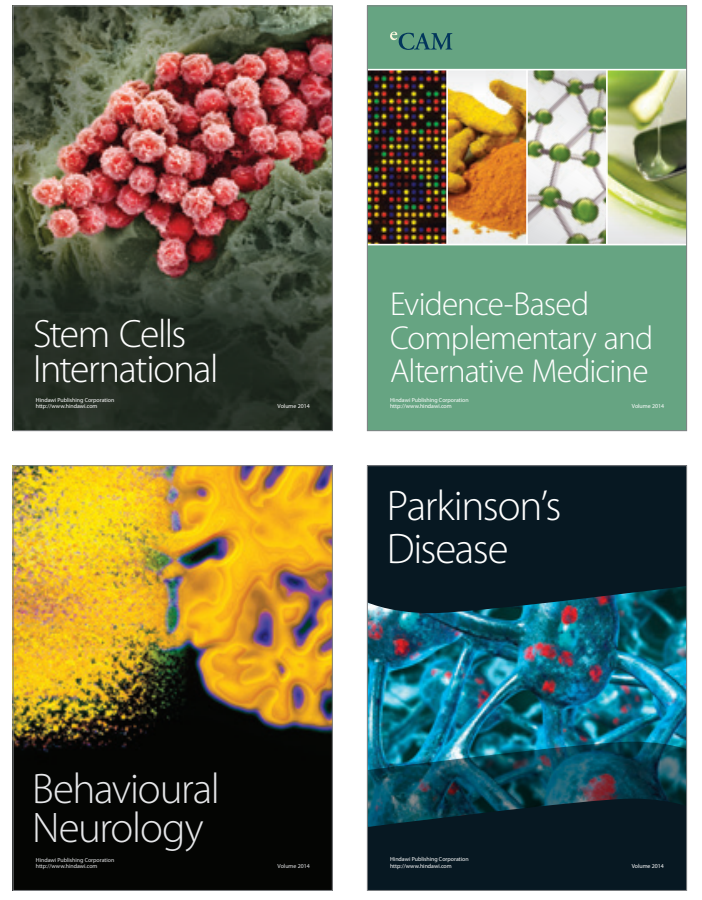
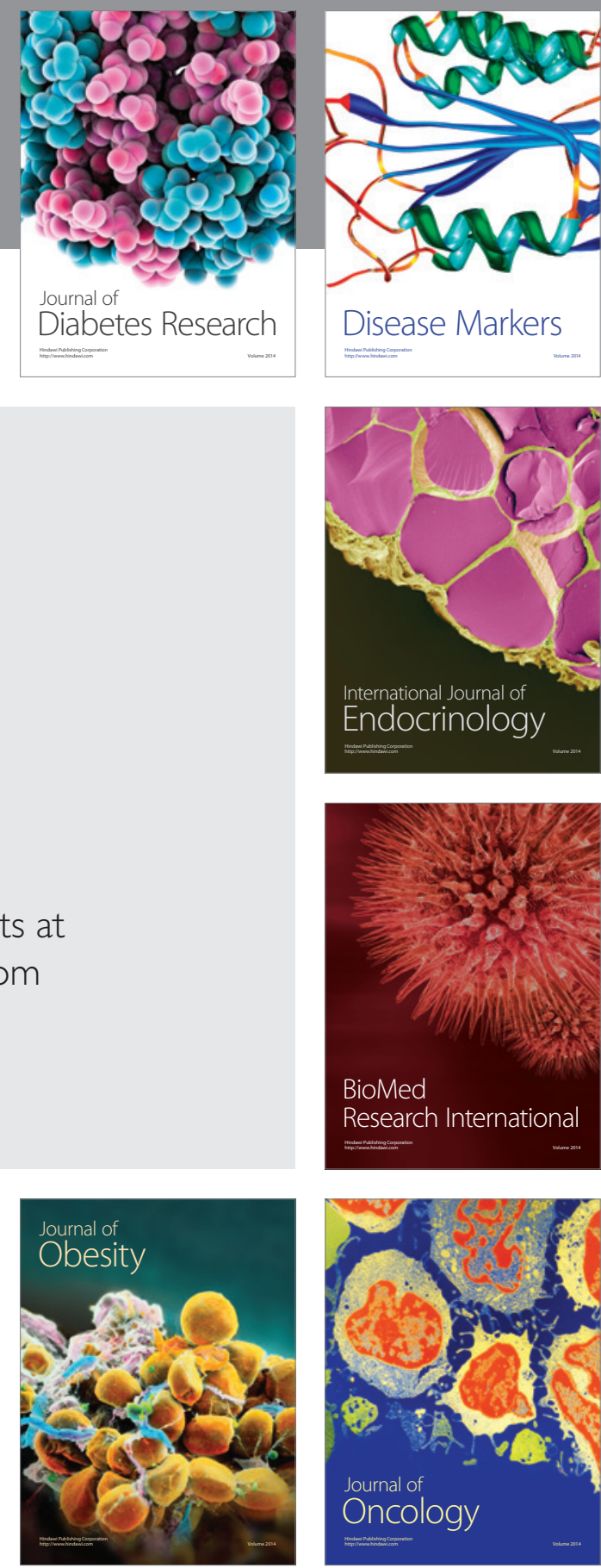

Disease Markers
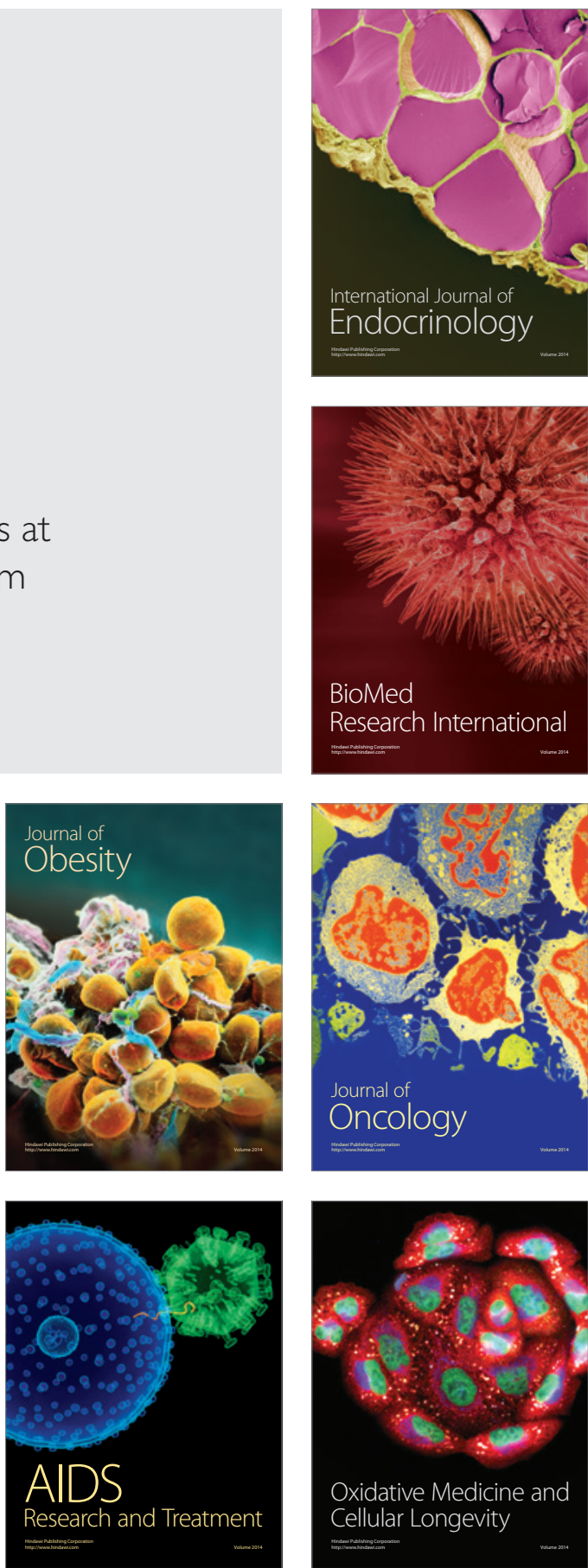